aliza o debate sobre o sistema de proteção social. A expressiva parcela de postos de trabalho informais era um elemento estrutural que diferenciava o Brasil dos países com sistemas universais. Esse fenômeno revitaliza o debate sobre o sistema de proteção social. Os mesmos especialistas que desde o governo FHC exercem forte influência e levam adiante as políticas focalizadas, nesse momento ocupam cargos no Instituto de Pesquisa Econômica Aplicada (IPEA) e postulam que o fato de termos nos tornado um "país de classe média" induz à privatização da saúde 4 . A relação causal seria intuitiva, a melhoria da renda individual e familiar induz a opção por alternativas assistenciais personalizadas, customizadas, de qualidade superior, portanto privadas.

No restante do mundo, a ascensão das massas trabalhadoras a melhores condições de vida originou tanto sistemas públicos de saúde robustos quanto a portentosa indústria de seguros saúde nos Estados Unidos. Portanto, as previsões sobre a inclinação natural do sistema brasileiro de saúde pelo mercado, não se baseia nem nas coisas da lógica nem na lógica das coisas e sim numa extravagante mistura de dois ingredientes: a tentativa de comprovar a existência de uma "nova classe média” mediante a exibição do aumento das coberturas de planos de saúde como indicador de mudança de status de classe social com as intenções de agentes do mercado de expandir seus negócios. Logo, o Brasil não está predestinado à privatização da saúde. Os manifestantes que foram às ruas recentemente reafirmaram suas "preferências" pelo SUS.

Em 1988, Francisco de Oliveira escreveu um artigo seminal intitulado O Surgimento do AntiValor 5 , no qual procura distinguir a marca do Estado de Bem-Estar Social no capitalismo. Seu principal argumento é o sistema de proteção social constitui um segundo momento do desenvolvimento do capitalismo. A diferença não recai sobre o uso de subsídios e auxílios públicos, na medida em que a vasta gama de suportes financeiros estatais para diversos setores e atividades é uma marca do próprio capitalismo ${ }^{6}$. A formação do sistema capitalista seria impensável sem a utilização de recursos públicos. Para este autor, o Welfare State representa uma "revolução copernicana”, nas relações estabelecidas entre trabalho e capital porque o fundo público passa a desempenhar uma função ex-ante das condições de reprodução de cada capital particular e das condições de vida, em lugar de seu caráter $e x$ post típico do capitalismo concorrencial.

Os argumentos dos neoliberais e de retóricos antineoliberais se fundamentam nas teses sobre os malefícios da redistribuição dos resultados da produção social mediante extração de recursos

para o fundo público sobre os investimentos privados. Porém é essa voracidade que, deixada entregue a si mesma, desnatura a democracia e o sentido de igualdade nela inscrito desde os tempos modernos. Ao nos convidar para remar contra as iniquidades em saúde e desencadear novas ações políticas, Paim nos leva a (re)conhecer os imensos esforços teóricos que embalaram o projeto do SUS constitucional. Reinventá-lo é tarefa para muitos e requer estudar profundamente a demarcação da utilização e distribuição da riqueza pública para "desencadear novas ações políticas".

1. World Bank. Financing health services in developing countries: an agenda for reform. Washington DC: World Bank; 1987.

2. Nobre M. Indeterminação e estabilidade: os 20 anos da Constituição Federal e as tarefas da pesquisa em direito. Novos Estudos 2008; (82):97-106.

3. Polanyi $\mathrm{K}$, organizador. A subsistência do homem e ensaios correlatos. Rio de Janeiro: Contraponto; 2012.

4. Secretaria de Assuntos Estratégicos. Presidência da República. Vozes da classe média: é ouvindo a população que se constroem políticas adequadas. http://www.sae.gov.br/site/?p=13433.

5. Oliveira F. O surgimento do anti-valor: capital, força e trabalho e fundo público. Novos Estudos 1988; (22):8-28.

6. Barr N. Economics of the welfare state. London: Oxford University Press; 2012.

http://dx.doi.org/10.1590/0102-311XCO041013

Ana Luiza d'Ávila
Viana

Faculdade de Medicina, Universidade de São Paulo, São Paulo, Brasil. analuizaviana@usp.br

\section{Longos dias têm cem anos}

Refletir e escrever sobre o lúcido artigo de Paim, após os episódios de junho/julho de 2013, introduz dupla responsabilidade: primeiro, comentar e refletir sobre os paradoxos e perguntas expostas pelo texto; segundo, lê-lo com uma perspectiva histórica, incluindo uma pequeníssima história, apenas do ponto de vista do tempo, os acontecimentos recentes.

Qualquer dia antes e após as manifestações de massa de junho/julho parece separar um longo espaço de tempo, quase uma eternidade, semelhante ao adágio "longos dias têm cem anos", título do romance de Augustina Bessa-Luís 1, escritora portuguesa contemporânea.

A ideia do adágio, conhecida expressão popular portuguesa, expressa que determinadas coisas levam tempo para maturar, o que pode 
explicar o longo período de silêncio dos protagonistas - os cidadãos - na luta por melhores serviços públicos (educação, saúde e transporte), melhores condições de vida, ampliação da democracia e da ética na política e na vida em sociedade. André Singer 2, na sua coluna no jornal Folha de S. Paulo, de 6 de abril de 2013, comentava que os futuros momentos políticos (dos próximos governos) colocarão para os (novos) governantes desafios imensos e intensos, quando aqueles beneficiados pelas recentes políticas de inclusão social vierem cobrar melhores empregos, e acrescento o que pensei na época, também irão cobrar melhores serviços públicos, qualidade e não somente expansão quantitativa, mas uma expansão qualificada, porque voltada ao encurtamento das desigualdades de todas as espécies, democratização dos processos de escolha de políticas públicas, inclusão da ética no ato de fazer política e políticas públicas etc. O que surpreendeu o autor foi a chegada antecipada desse prognóstico. Como a todos nós.

Segundo Laura Pennacchi 3, no debate público e na mobilização política contemporânea duas questões ocupam a cena - a do bem comum e a da ética.

Bem comum, bens públicos, esfera pública, democracia, qualidade de vida, ética são questões interligadas, mas que carecem ainda de reflexão conjunta, de uma ação que interligue e dê sentido ao que juntas se propõem - uma nova sociedade baseada nos valores e princípios da igualdade, responsabilidade comum, justiça, liberdade e pertencimento social.

A questão do bem comum, aquilo que não é propriedade de ninguém, como água, o ar, o clima, os recursos minerais do fundo marinho, a biodiversidade, o conhecimento e a cultura, a órbita celeste, as instituições, as regras, as normas e o capital social, aflora com nitidez depois dos processos de globalização e financeirização, que introduziram valores de mercado e individualistas na vida social, anulando o papel do bem comum como pressuposto necessário da vida social.

O paradigma do homem econômico - individualista e autointeressado - deixou o sentido de bem somente na esfera da valorização do mercado e a reprodução da vida somente como objeto da técnica e da racionalidade econômica.

A construção conjunta entre trabalho-cidadão-welfare produziu a negação de uma cidadania censitária, de forma a garantir a todos os cidadãos condições de igualdade na relação com o mercado e o reconhecimento de uma propriedade coletiva em substituição à propriedade individual.

O SUS e o capítulo da Seguridade Social na Constituição de 1988 são apenas uma primeira representação dessas propostas de responsabilização coletiva pelos destinos do outro, de criação de um tecido social solidário e coeso, voltado a cumprir com princípios de solidariedade social.

A não concretização dos dois projetos desenhados e formulados ainda na conjuntura dos anos 80 do século $\mathrm{XX}$, em um período histórico singular, caracterizado pela crise econômica e do modelo de desenvolvimento (da segunda metade do século $\mathrm{XX}$ ), por um lado, e processo de democratização da política e da sociedade, após quase 20 anos de regime autoritário, por outro, mesmo nos períodos políticos em que os formuladores dessas propostas foram governo, constitui o paradoxo.

Por que a ideia da construção de uma propriedade social que subtrairia dos ombros dos indivíduos a responsabilidade pela cobertura dos riscos social (adoecer, envelhecer, ser excluído) foi transformada em uma sorte de pequenas políticas e estratégias que conduziram ao aprofundamento da ideia da saúde como mercadoria?

São recorrentes na bibliografia nacional e internacional caracterizar os acontecimentos dos anos 80 e 90 do século passado e primeira década do século XXI, os 30 anos da ordem neoliberal, por três processos que o geraram e o constituíram: a financeirização, a mercadorização e a desnormatização.

Eles incidiram fortemente sobre a noção de bem comum, mercantilizando e mercadorizando o que sempre esteve fora da órbita do mercado, mesclando as fronteiras entre valor de uso e valor de troca, invadindo toda a vida social, desde os aspectos mais comuns (como os bens públicos) até os mais privados e diferenciados (na órbita das relações pessoais), como afirma W. Streek 4, em artigo na revista Piauí de abril desse ano, com o sugestivo título, O Cidadão como Consumidor. Considerações sobre a Invasão da Política pelo Mercado.

A política de saúde esteve envolta nesse círculo/circuito de mercadorização e financeirização, pois foi umas das que mais se viu exposta aos ditames do mercado: primeiro, porque sofreu nos anos mais recentes uma avassaladora incorporação tecnológica de base industrial, resultando num produto final (produto de saúde, soma de todas as atividades diretas e indiretas em saúde), constituído por insumos e equipamentos industriais de alto valor agregado, e pela crescente participação de honorários referentes às habilidades pessoais e especializadas - uma oferta quase monopolista - de alguns profissionais, sem contar com as novas receitas auferidas pelas intricadas instâncias de intermediação financeira entre usuários e provedores, como são os planos e as empresas de administração de planos e seguros 
de saúde. Produto esse que conta quando transformado em lucro e salário com grossos subsídios públicos na forma de isenção fiscal, crédito subsidiado para investimentos e programas específicos de transferência financeira.

Contudo, a política de saúde faz parte (ainda) do escopo de bens públicos e sua oferta equitativa é garantia de um padrão de vida social que coloque a reprodução humana fora da órbita do privado e do mercado, constituindo uma base sólida de coesão e pertencimento social e coletivo.

Essa é sua grande contradição: como manter a incorporação tecnológica de forma a torná-la cada vez mais um instrumento da equidade; de que forma iniciar/voltar a respeitar decisões éticas e democráticas nas escolhas públicas, e, finalmente, como continuar a ser parte integrante dos grandes e generosos sistemas de proteção social que garantiram a ascensão social e a vida em sociedade no século XX.

Aqui, a falta de tradição de um estado social redistributivo, os ganhos extraordinários e exponenciais de alguns atores integrantes da política (provedores de serviços, produtores de medicamentos, insumos e equipamentos e intermediários financeiros), as lutas e disputas desiguais pelos (parcos) recursos, e a influência desses interesses nas decisões políticas, explicam, em parte, a situação atual.

A disputa distributiva entre lucro e salário pelas rendas geradas pela política de saúde foi ganha pelo lucro: o lucro dos grandes hospitais privados; os ganhos extraordinários de alguns pouco profissionais tops - os CEOS da saúde -, em duplo sentido, o que introduziu clivagens imensas entre os salários dos profissionais médicos e dos administradores de diferentes áreas; o volumoso lucro das indústrias do complexo econômico industrial da saúde; ao lado de ganhos crescentes dos intermediários financeiros. Esses são os defensores do status quo, aqueles que não querem mudanças porque lucram muito com a política atual - mercadorizada, desregulamentada e desigual. É isso que explica o paradoxo, o alinhamento da política de saúde com a permanência de lucros extraordinários para poucos e o descumprimento dos valores da solidariedade social.

Novas frentes têm se formado em oposição à coalizão ganhadora dos últimos anos no interior da política de saúde: os trabalhadores da saúde que não usufruem os ganhos extraordinários, nem mesmo recebem salários e provimentos justos, os cidadãos que sofrem na busca de uma saúde de qualidade, os gestores responsáveis, com pouca margem de manobra frente aos interesses corporativos (de empresas e profissionais altamente qualificados e diferenciados etc.).

A política precisa domar os interesses do capital na área da saúde, para que ganhe poder, pois o momento atual é aquele em que o econômico se liberta da política e a política fica destituída de poder. Gestores sem poder e interesses corporativos pautando as decisões da política, é o que se vê nos diferentes níveis de governo.

É necessário que os episódios recentes estimulem e sirvam para libertar os dirigentes dessas amarras e condicionantes únicos da política e lhes tragam robustez para buscar de maneira compartilhada novas frentes e novos aliados, a fim de enfrentar o desafio de integrar com virtuosidade as relações entre bem comum, bem público, democracia e ética.

O texto de Paim nos inspira e guia nessa direção.

1. Bessa-Luís A. Longos dias têm cem anos. Lisboa: Imprensa Nacional Casa da Moeda; 1982.

2. Singer A. Indústria e voto. Folha de S. Paulo 2013; 6 abr.

3. Pennachi L. Filosofia dei beni comuni. Crisi e primato della sfera pubblica. Roma: Donzelli Editore; 2012.

4. Streek W. O cidadão como consumidor. Considerações sobre a invasão da política pelo mercado. Revista Piauí 2013; (79):60-5.

http://dx.doi.org/10.1590/0102-311XCO051013

\section{Celia Almeida}

Escola Nacional de Saúde Pública Sergio Arouca, Fundação Oswaldo Cruz, Rio de Janeiro, Brasil. calmeida@ensp.fiocruz.br

\section{Os 25 anos do SUS: desencanto ou oportunidade?}

O texto do Paim é um convite à reflexão.

Entender (e reconstruir) a gênese de qualquer evento é essencial, como bem assinala o autor, pois todo processo tem um "ponto de partida" (aparentemente conhecido) e um "ponto de chegada", que quase nunca é exatamente aquele que se pretendia, e significa, não raro, novas e permanentes reatualizações, numa história sem fim.

Em se tratando de um processo político (formulação, criação e consolidação do SUS, como parte da luta pela democracia no Brasil) e acolhendo a reflexão sobre a "utopia prática" de Bourdieu, proposta pelo artigo, arrisco acrescentar algumas questões como contribuição ao debate, com o objetivo de problematizar o que se concretizou, entre os demais "desfechos" possíveis e, talvez, vislumbrar "alguma luz no fim do túnel”. 